\title{
Correction to: Accuracy and Reliability of Multiphase CTA Perfusion for Identifying Ischemic Core
}

\author{
Meaghan Reid ${ }^{1,2}$ - Akinrinola O. Famuyide ${ }^{3,4}$ - Nils D. Forkert ${ }^{2,3,4}$ - Aron Sahand Talai • James W. Evans ${ }^{5}$. \\ Amith Sitaram ${ }^{2,3}$. Moiz Hafeez ${ }^{1,2}$ - Mohamed Najm² $\cdot$ Bijoy K. Menon ${ }^{2,3,6}$. Andrew Demchuk ${ }^{2,3}$. \\ Mayank Goyal ${ }^{2,3,4} \cdot$ Rani Gupta Sah ${ }^{2,3,4} \cdot$ Christopher D. d'Esterre ${ }^{2,3,4} \cdot$ Philip Barber2,3,4
}

Published online: 3 June 2019

๑) Springer-Verlag GmbH Germany, part of Springer Nature 2019

\section{Correction to:}

\section{Clin Neuroradiol 2018}

https://doi.org/10.1007/s00062-018-0717-x

Unfortunately, the author list of the original version of this article contains a mistake. The middle name of the author "Rani Gupta Sah" was erroneously tagged as part of the surname in the article's metadata.

This mistake has been corrected and the author list is now correct.

The online version of the original article can be found under https://doi.org/10.1007/s00062-018-0717-x.

$\triangle$ Philip Barber

pabarber@ucalgary.ca

1 Department of Medical Sciences, University of Calgary,

Calgary, Canada

2 Calgary Stroke Program, Department of Clinical

Neurosciences, University of Calgary, 3330 Hospital Drive NW, AB T2N 4N1 Calgary, Canada

3 Seaman Family Center, University of Calgary, Calgary, Canada

4 Department of Radiology, University of Calgary, Calgary, Canada

5 Department of Neurosciences, Gosford Hospital, Gosford, Australia

6 Department of Community Health Sciences, University of Calgary, Calgary, Canada 